\title{
Valores energéticos de rações expandidas em diferentes temperaturas para frangos de corte
}

\author{
[Energy values of expander feed in different temperatures for broilers] \\ M.F. Lima ${ }^{1 *}$, H.P. Couto ${ }^{2}$, G.S.C.P. Corte Real ${ }^{3}$, R.T.R.N. Soares ${ }^{2}$, \\ A.V.C. Gomes ${ }^{4}$, F.A. Curvello ${ }^{4}$

\begin{abstract}
${ }^{1}$ Instituto Federal de Educação - Ciência e Tecnologia do Rio de Janeiro - Pinheiral, RJ
${ }^{2}$ Universidade Estadual do Norte Fluminense Darcy Ribeiro-UENF - Campos dos Goytacazes, RJ

${ }^{3}$ Aluna de pós-graduação - Universidade Estadual do Norte Fluminense Darcy Ribeiro - Campos dos Goytacazes, RJ

${ }^{4}$ Universidade Federal Rural do Rio de Janeiro - Instituto de Zootecnia - IZ-UFRRJ - Seropédica, RJ
\end{abstract}

\section{RESUMO}

O objetivo deste estudo foi determinar os valores energéticos de rações expandidas, obtidas em diferentes temperaturas de expansão para frangos de corte em diferentes idades. As rações foram expandidas nas temperaturas: $80 ; 100 ; 120 ; 140^{\circ} \mathrm{C}$. Dois ensaios biológicos foram conduzidos utilizando-se o método tradicional de coleta total de excretas para determinar a energia metabolizável aparente corrigida (EMAn). Os ensaios metabólicos foram conduzidos com pintos machos Cobb, de 11 a 19 dias (fase inicial) e de 27 a 35 dias de idade (fase de crescimento), utilizando-se as mesmas aves do primeiro ensaio e, assim, preservando os tratamentos a que foram submetidas. Os valores da EMAn das rações da fase inicial foram: 2937; 2900; 2806 e 2751kcal $/ \mathrm{kg}$, e da fase de crescimento: 3045; 3031; 3115 e $2977 \mathrm{kcal} / \mathrm{kg}$, respectivamente. Os resultados mostraram uma redução linear dos níveis de EMn com o aumento da temperatura de expansão na idade de 11 a 19 dias. As perdas relativas entre as rações expandidas a 80 e $100^{\circ} \mathrm{C}$ foram mínimas, enquanto nas temperaturas de 120 e $140^{\circ} \mathrm{C}$ foram significativamente superiores. No ensaio de metabolismo para a fase de crescimento, verificou-se que as perdas relativas entre as rações expandidas a 80 e $100^{\circ} \mathrm{C}$ foram pequenas $(-14 \mathrm{kcal})$. Para a ração expandida a $120^{\circ} \mathrm{C}$, o valor energético foi superior $(84 \mathrm{kcal})$, enquanto para $140^{\circ} \mathrm{C}$ foi significativamente inferior (-138kcal). Esses resultados mostram que, na fase de crescimento, os frangos de corte maximizaram o aproveitamento energético das rações na temperatura de expansão de $120^{\circ} \mathrm{C}$ e que, em temperaturas acima desse nível, ocorrem altas perdas da EMAn das rações, que podem comprometer o consumo, a deposição de proteína e a conversão alimentar e, consequentemente, trazer grandes prejuízos econômicos pelo menos à idade de abate. As temperaturas de expansão de rações entre 80 e $100^{\circ} \mathrm{C}$ apresentaram os melhores valores de EMAn para frangos com idade entre 15 e 10 dias, enquanto para idade de 31 a 35 dias foi de $120^{\circ} \mathrm{C}$.

Palavras-chave: aves, energia metabolizável, expander, rações

\begin{abstract}
The aim of this study was to determine the energetic value of feed in different expansion temperatures for broilers of different ages. The feedexpanded in the following temperatures: 80; 100, 120 and $140^{\circ} \mathrm{C}$. Two biological assays were run to establish apparent metabolizable energy corrected by nitrogen balance $\left(A M E_{N}\right)$ using the traditional total excreta collection method. In the first assay Cobb chicks were used from 11 to 19 days of age (initial period), and 29 to 37 days of age (growth period), as well as the same treatments of the first assay. The $A M E_{N}$ values for the initial period were respectively: 2937, 2900, 2806 and $2751 \mathrm{kcal} / \mathrm{kg}$; and broilers in growing period were respectively: 3045, 3031, 3115 and $2977 \mathrm{kcal} / \mathrm{kg}$. The results showed a linear decrease of the levels $E M A_{N}$ with an increase of the temperature of expansion
\end{abstract}

Recebido em 28 de julho de 2014

Aceito em 3 de dezembro de 2015

* Autor para correspondência (corresponding author)

E-mail: marcos.lima@ifrj.edu.br 
from 11 to 19 days old. The loss relation between feed expanded at 80 and $100^{\circ} \mathrm{C}$ were minimal, while in temperatures between 120 and $140^{\circ} \mathrm{C}$ they were significantly higher. In the metabolic assay for period growth, we observed that the relation of energy values between feed expanded at 80 and $100^{\circ} \mathrm{C}$ were smaller (14 kcal), while for the expanded in $120^{\circ} \mathrm{C}$ they were superior $(84 \mathrm{kcal})$, and at $140^{\circ} \mathrm{C}$ were inferior (138 kcal). These results suggest greater energy utilization efficiency in period growth at a temperature of $120^{\circ} \mathrm{C}$, while in temperatures above of this level there was greater loss of $E M A_{N}$ in feeds, which can prejudice feed intake, protein deposition and feed conversion, and consequently damage economics by increasing slaughter age. The expansion temperatures in feed between 80 and $100^{\circ} \mathrm{C}$ showed the best $E M A_{N}$ values for broilers with 15 - 19 days of age, while for 31 - 35 days old it was 120 ${ }^{\circ} \mathrm{C}$.

Keywords: energy, expander, feed, metabolizable, poultry

\section{INTRODUÇÃO}

$\mathrm{O}$ processamento de alimentos por temperatura, pressão e umidade causa alterações físicas no amido, promovendo a chamada "gelatinização", que é a liberação da amilose e da amilopectina, bem como a ruptura da parede celular dos vegetais, facilitando a digestão enzimática do amido (Van, 1994). A gelatinização pode ainda ser definida como a destruição irreversível da condição cristalina do grão de amido, de modo que a superfície de toda molécula fique acessível ao ataque de reagentes, solventes e enzimas.

O processo aumenta a velocidade enzimática das amilases, que são responsáveis pela hidrólise da molécula de amido em carboidratos mais simples e solúveis, fazendo com que seja absorvida maior quantidade de água, o que promove aumento no coeficiente de digestibilidade e, consequentemente, melhora o ganho de peso e a conversão alimentar de frangos de corte.

Ao se submeterem os alimentos ao processamento por aquecimento, tem-se como principal objetivo a melhoria na digestibilidade e/ou na disponibilidade dos nutrientes (Budiño et al., 2000). O nível de melhoria na digestibilidade dos nutrientes depende do próprio alimento, do tipo de processamento, do tempo e da temperatura de aquecimento, da umidade do alimento, do tamanho da partícula e do nível de inclusão do alimento na ração (Moreira et al., 1994).

$\mathrm{O}$ amido dos cereais, quando processado por extrusão, devido a suas características, contribui na expansão e coesão do produto final, além de ser gelatinizado (Amaral, 2002). Temperaturas de 50 a $80^{\circ} \mathrm{C}$ são capazes de interferir na solubilidade do amido, melhorando a absorção de água por essa molécula (Goelema et al., 1999). As barreiras físicas para a digestão do amido incluem a cutícula da semente, a matriz proteica que envolve seus grânulos e a baixa solubilidade do amido por si só. Alguns processos, como a trituração, por exemplo, rompem a cutícula, mas, normalmente, têm pouco efeito sobre a matriz proteica que envolve o amido ou sobre sua solubilidade. A utilização mais completa do amido requer um maior grau de rompimento do grânulo de amido, que pode ser obtido por meio do processamento a vapor e por pressão. Os tratamentos que envolvem umidade, calor e pressão causam o rompimento da matriz proteica que recobre o grânulo de amido e aumentam a sua eficiência de utilização (Germany, 1992).

O principal fator que contribui para mudanças do amido é o vapor; assim, aumentando-se a pressão de vapor, aumenta-se o grau de gelatinização. $\mathrm{O}$ tempo maior de permanência da mistura no processo ocasiona melhor absorção da umidade e aumento no tamanho da partícula, devido à dilatação pela hidratação. $\mathrm{O}$ estudo do processo de gelatinização indica que os grânulos de amido sofrem inchamento e se rompem mais facilmente quando em presença de teores de água superiores a $40 \%$ e que há necessidade de aplicação de temperaturas mais elevadas quando o teor de água é mais baixo (Souza et al., 2000). Existem diversas formas de tratar termicamente os alimentos destinados à alimentação de frangos de corte, sendo os processos de peletização e expansão de rações os mais utilizados na atualidade.

Estudos sobre a tecnologia de tratamento hidrotérmico conhecida como expansão são escassos na literatura no Brasil. Poucas empresas, até o momento, utilizam essa 
tecnologia para produção de rações avícolas, contrariamente às concorrentes internacionalmente conhecidas. Nesse contexto, realizou-se o presente trabalho com o objetivo de determinar os valores energéticos de rações expandidas, obtidas em diferentes temperaturas de expansão para frangos de corte em diferentes idades.

\section{MATERIAL E MÉTODOS}

Foram realizados dois ensaios biológicos de determinação dos valores de energia metabolizável aparente corrigida pelo método tradicional de coleta total de excretas, utilizandose frangos de corte em duas fases de criação e alimentados com rações expandidas em diferentes temperaturas. Foram estudados quatro tipos de rações expandidas, oriundas da empresa Rica Alimentos, localizada no estado do Rio de Janeiro. As rações experimentais foram fornecidas nas diferentes idades: 11 a 19 dias (fase inicial) e 27 a 35 dias (fase de crescimento I). As exigências das aves e a composição química dos alimentos foram calculadas com base nas Tabelas Brasileiras para Aves e Suínos (Rostagno et al., 2005).

Durante o período experimental, as aves receberam diariamente 23 horas de iluminação, sendo a luz natural complementada com lâmpadas fluorescentes. Para o primeiro ensaio de metabolismo (aves com 11 a 19 dias), foram utilizados 144 pintos de corte, machos da linhagem Cobb 500. Esse ensaio ocorreu em bateria metálica com 24 divisões $(0,50$ x 1,00 metro) e seis aves por boxe, alocada em galpão de alvenaria coberto com telhas de barro, contendo um bebedouro automático tipo taça e um comedouro linear em cada unidade experimental.

As excretas foram coletadas em bandejas dispostas sob cada compartimento das gaiolas e revestidas com material plástico. Foram realizadas duas coletas ao dia, às oito e às 17 horas, evitando fermentações fecais. No término do período experimental, foi quantificada a ração consumida e a excreta total por repetição, durante os cinco dias de coleta. Na Tab. 1, está apresentada a composição alimentar e nutricional da ração experimental (oito a 21 dias)
Os tratamentos consistiram em: T1 - ração inicial expandida a temperatura de $80^{\circ} \mathrm{C}$; T2 ração inicial expandida a temperatura de $100^{\circ} \mathrm{C}$; T3 - ração inicial expandida a temperatura de $120^{\circ} \mathrm{C}$; T4 - ração inicial expandida a temperatura de $140^{\circ} \mathrm{C} . \quad \mathrm{O}$ delineamento experimental foi inteiramente ao acaso, com quatro tratamentos, sendo a ração submetida a quatro temperaturas de expansão, seis repetições e seis aves por unidade experimental, todas do mesmo sexo.

Após o término do primeiro ensaio de metabolismo, foram retiradas três aves de forma aleatória das gaiolas de metabolismo, permanecendo três aves por bateria até que atingissem a idade para o início do segundo ensaio. Quando as aves completaram 27 dias de idade, com peso médio de $1,500 \mathrm{~kg}$, foram transferidas para as gaiolas de metabolismo do segundo ensaio, com as dimensões 50 × 50 x $41 \mathrm{~cm}$, providas de comedouro linear individual e bebedouros tipo nipple. A unidade experimental foi constituída por três animais machos por gaiola. Nesse segundo ensaio, as aves foram submetidas a quatro dias de adaptação às instalações (do $27^{\circ}$ ao $30^{\circ}$ dia) e a cinco dias de coleta total de excretas (do $31^{\circ}$ ao $35^{\circ}$ dia). As excretas foram coletadas utilizando-se a mesma metodologia do primeiro ensaio. Foram monitoradas as condições ambientais por meio de termômetro de máxima e mínima.

$\mathrm{Na}$ Tab. 2, está apresentada a composição alimentar e nutricional calculada da ração experimental (22 a 35 dias). As excretas coletadas em ambos os ensaios foram acondicionadas em sacos plásticos devidamente identificados e armazenados em freezer até o final do período experimental. Posteriormente, as amostras foram descongeladas, pesadas, homogeneizadas, e retiraram-se subamostras para análises laboratoriais. Foi realizada a présecagem em estufa ventilada a $55^{\circ} \mathrm{C}$ e subsequentes análises de matéria seca (MS), nitrogênio $(\mathrm{N})$ e energia bruta $(\mathrm{EB})$ por meio da bomba calorimétrica tipo Parr. Os valores de energia metabolizável aparente (EMA) e aparente corrigida pelo balanço de nitrogênio (EMAn) foram calculados utilizando-se as equações propostas por Matterson et al. (1995). 


\section{Lima et al.}

Tabela 1. Composição alimentar e nutricional da ração do ensaio I (pintos machos - 11 a 19 dias - fase inicial)

\begin{tabular}{|c|c|c|c|}
\hline Ingredientes & $\%$ & Composição calculada & \\
\hline Milho & 61,900 & E M (kcal/kg) & 2921 \\
\hline Farelo de soja & 30,940 & Proteína bruta $(\%)$ & 21,80 \\
\hline Far. carne e ossos & 5,620 & Metionina digestível (\%) & 0,50 \\
\hline Sal & 0,367 & Metionina + cistina digestível $(\%)$ & 0,85 \\
\hline Calcário & 0,060 & Lisina digestível (\%) & 1,30 \\
\hline L-Lisina. $\mathrm{HCl}$ & 0,210 & Cálcio (\%) & 0,98 \\
\hline Colina & 0,050 & Fósforo disponível (\%) & 0,48 \\
\hline DL- Metionina & 0,353 & & \\
\hline Antioxidante & 0,100 & & \\
\hline Premix ${ }^{1}$ & 0,400 & & \\
\hline
\end{tabular}

Tabela 2. Composição alimentar e nutricional da ração do ensaio II (pintos machos - 27 a 35 dias - fase crescimento)

\begin{tabular}{|c|c|c|c|}
\hline Ingredientes & $\%$ & Composição calculada & \\
\hline Milho & 63,830 & E M (kcal/kg) & 3019 \\
\hline Farelo de soja & 27,820 & Proteína bruta $(\%)$ & 20,50 \\
\hline Far. carne e ossos & 0,230 & Metionina digestível (\%) & 0,48 \\
\hline Sal & 5,500 & Metionina + cistina digestível $(\%)$ & 0,75 \\
\hline Calcário & 1,000 & Lisina digestível (\%) & 1,00 \\
\hline L-Lisina. $\mathrm{HCl}$ & 0,367 & Cálcio (\%) & 0,96 \\
\hline Colina & 0,083 & Fósforo disponível (\%) & 0,46 \\
\hline DL- Metionina & 0,263 & & 3019 \\
\hline Antioxidante & 0,055 & & \\
\hline Premix $^{1}$ & 0,352 & & \\
\hline \multicolumn{4}{|c|}{$\begin{array}{l}{ }^{1} \text { Composição/kg de premix }{ }^{1} \text { vit. A, 3.000UI; vit. D3, 875UI; vit. E, } 10.000 \mathrm{UI} \text {; vit. K3, } 1.000 \mathrm{mg} \text {; vit. B1, } 1.000 \mathrm{mg} \text {; } \\
\text { vit.B2, 2.500mg; vit. B6, } 1.625 \mathrm{mg} \text {; vit.B12, 5.000mg; ác. pantotênico, 5.000mg; niacina, 12.500mg; ác. fólico, } \\
\text { 625mg; biotina, 55mg; manganês, 30.000ppm; zinco, 25.000ppm; ferro, } 16.250 \text { sppm; cobre, 2.500ppm; iodo; } \\
\text { 375ppm; Selênio, 87,500ppm; monenzina, } 16.250 \mathrm{mg} \text {; nicarbazina, 16..250mg; antimicrobiano (colistina, 6.250mg; } \\
\text { enramicina, 2.500mg); antioxidante, } 166,5 \mathrm{mg} \text {. }\end{array}$} \\
\hline
\end{tabular}

\section{RESULTADOS E DISCUSSÃO}

Os resultados do ensaio de metabolismo estão apresentados na Tab. 3. Os valores da energia metabolizável aparente corrigida (EMAn) para as temperaturas de expansão de $80,100,120$ e $140^{\circ} \mathrm{C}$ foram: $2937 ; 2900 ; 2806$ e $2751 \mathrm{kcal} / \mathrm{kg}$ de ração, respectivamente. Observa-se uma redução linear dos níveis de EMAn com o aumento da temperatura de expansão (Fig. 1). Verificou-se 
que a EMAn, determinada nas rações expandidas a 80 e $100^{\circ} \mathrm{C}$, apresentou valores semelhantes ao apresentado pela formulação de ração da fase inicial $(2920 \mathrm{kcal} / \mathrm{kg})$, superior em $17 \mathrm{kcal}$ $(0,58 \%)$ e inferior em $20 \mathrm{kcal}(0,68 \%)$, respectivamente. Entretanto, para a expansão a 120 e $140^{\circ} \mathrm{C}$, verificaram-se níveis energéticos significativamente inferiores, $114 \mathrm{kcal}(-3,90 \%) \mathrm{e}$ $169 \mathrm{kcal} \quad(-5,79 \%)$, respectivamente. Nas comparações realizadas entre os valores da EMAn obtida nas diferentes temperaturas de expansão, observou-se que as perdas relativas entre as rações expandidas a 80 e $100^{\circ} \mathrm{C}$ foram minimizadas em $37 \mathrm{kcal}(1,26 \%)$, enquanto para as expandidas a 120 e $140^{\circ} \mathrm{C}$, foram significativamente superiores em $131 \mathrm{kcal}$ $(4,46 \%)$ e $186 \mathrm{kcal}(6,33 \%)$, respectivamente.

Esses resultados demonstram que, na fase inicial (15-19dias), pintos de corte maximizaram o aproveitamento energético das rações na faixa de temperatura de expansão entre 80 e $100^{\circ}$, e que, em temperaturas acima de $120^{\circ} \mathrm{C}$, ocorrem altas perdas energéticas nas rações, que podem comprometer a taxa de crescimento das aves nessa fase de desenvolvimento. Os baixos coeficientes de variação observados entre as determinações da EMAn entre repetições confirmam a confiabilidade dos resultados (Tab. 3).

É notório que, durante os processamentos térmicos, os alimentos passem por uma transformação que altera as moléculas que os constituem. Germany (1992) relata que a passagem do amido pelo expander proporciona sua hidrolisação devido aos efeitos do calor, da pressão e da umidade, o que facilita sua digestão enzimática. Quanto à proteína, este mesmo autor relata aumento de sua digestibilidade nos alimentos expandidos, pois a modificação na sua estrutura terciária provoca uma redução no tempo de hidrólise no intestino das aves. Portanto, o aumento da digestibilidade do amido e a maior solubilidade das proteínas foram responsáveis pelo aumento da EMAn das rações expandidas observadas neste ensaio. O calor excessivo durante os tratamentos hidrotérmicos é causa de significativas perdas nutricionais.

Segundo Germany (1992), alimentos proteicos de origem vegetal reduzem sua solubilidade pelo seu menor PDI (índice de dispersibilidade proteica). A provável causa é a aglomeração da proteína por ligações químicas cruzadas, que não podem ser hidrolisadas pelas enzimas endógenas. Entretanto, o autor relata que, em alimentos muito ricos em amido, nenhuma pesquisa mostrou que a expansão causa prejuízos na proteína, tais como nas disponibilidades dos aminoácidos. Os resultados demonstraram que, em temperaturas acima de $120^{\circ} \mathrm{C}$, os valores da EMAn foram acentuadamente reduzidos e que as moléculas de amido sofreram um processo de deteriorização e provavelmente tornaram a proteína menos solúvel. Esses resultados também mostram que a utilização de temperatura adequada no expander pode otimizar a digestão amilácea, maximizando a EMAn. Segundo Nitsan (1991), a atividade máxima da amilase pancreática no conteúdo intestinal dos pintos ocorre aproximadamente aos 17 dias, idade média de realização do ensaio metabólico.

Tabela 3. Valores da energia metabolizável corrigida das rações iniciais de frangos de corte (15-19 dias) para as diferentes temperaturas de expansão

\begin{tabular}{ccccccc}
\hline $\begin{array}{c}\text { Temperatura de } \\
\text { expansão }\end{array}$ & $\begin{array}{c}\text { Energia } \\
\text { metabolizável }\end{array}$ & $* \mathrm{CV}$ & \multicolumn{2}{c}{$\begin{array}{c}\text { Relativo à energia } \\
\text { metabolizável formulada }\end{array}$} & $\begin{array}{c}\text { Relativo à energia } \\
\text { metabolizável dos } \\
\text { tratamentos }\end{array}$ \\
\hline${ }^{\circ} \mathrm{C}$ & $\mathrm{kcal} / \mathrm{kg}$ & $\%$ & $\mathrm{kcal} / \mathrm{kg}$ & $\%$ & $\mathrm{kcal} / \mathrm{kg}$ & $\%$ \\
80 & 2937 & 4,20 & 17 & 0,58 & - & - \\
100 & 2900 & 4,79 & -20 & 0,68 & 37 & $-1,26$ \\
120 & 2806 & 2,39 & -114 & 3,90 & 131 & $-4,46$ \\
140 & 2751 & 1,23 & -169 & 5,79 & 186 & $-6,33$ \\
\hline
\end{tabular}

*CV: Coeficiente de variação. 


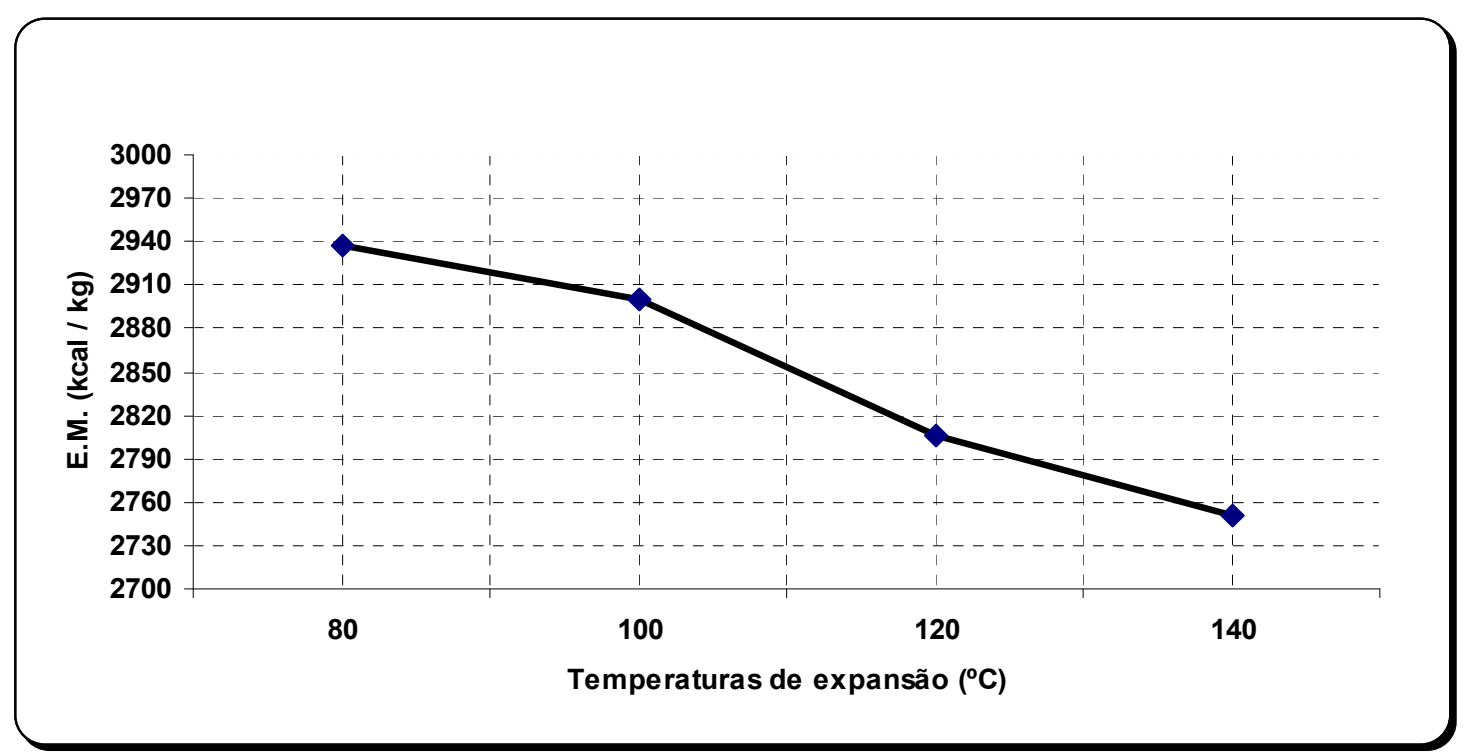

Figura 1. Valores da EMAn das rações iniciais de frangos de corte (15-19 dias) para as diferentes temperaturas de expansão.

Os resultados do segundo ensaio de metabolismo estão apresentados na Tab. 4. Os valores da energia metabolizável corrigida (EMAn) para as temperaturas de expansão de $80,100,120$ e $140^{\circ} \mathrm{C}$ foram: $3045 ; 3031 ; 3115$ e $2977 \mathrm{kcal} / \mathrm{kg}$ de ração, respectivamente. Observa-se um aumento da EMAn na temperatura de expansão de $120^{\circ} \mathrm{C}$, com uma acentuada redução para o nível de $140^{\circ} \mathrm{C}$ (Fig. 2).

Verificou-se que a EMAn, determinada nas rações expandidas a 80 e $100^{\circ} \mathrm{C}$, apresentou valores semelhantes ao apresentado pela formulação de ração da fase de crescimento $(3020 \mathrm{kcal} / \mathrm{kg})$, superiores em $25 \mathrm{kcal}(0,83 \%)$ e $11 \mathrm{kcal}(0,36 \%)$, respectivamente. Entretanto, para a expansão a $120^{\circ} \mathrm{C}$, verificou-se o nível energético relativo significativamente superior, aproximadamente $95 \mathrm{kcal}(3,14 \%)$, enquanto para a expansão a $140^{\circ} \mathrm{C}$, a EMAn relativa decresceu drasticamente, cerca de $43 \mathrm{kcal}(-1,43 \%)$. Nas comparações realizadas entre os valores da EMAn obtida nas diferentes temperaturas de expansão, observou-se que as perdas relativas entre as rações expandidas a 80 e $100^{\circ} \mathrm{C}$ foram reduzidas em apenas $14 \mathrm{kcal}(-0,47 \%)$, enquanto para as expandidas a $120^{\circ} \mathrm{C}$ foram superiores em $84 \mathrm{kcal}(2,29 \%)$, e para a de $140^{\circ} \mathrm{C}$ inferiores significativamente em 138 (-2,23\%), respectivamente. Os baixos coeficientes de variação observados entre as determinações da EMAn entre repetições confirmam a confiabilidade dos resultados (Tab. 4).

Tabela 4. Valores da energia metabolizável corrigida das rações de crescimento de frangos de corte (3135 dias) para as diferentes temperaturas de expansão

\begin{tabular}{ccccccc}
$\begin{array}{c}\text { Temperatura } \\
\text { de expansão }\end{array}$ & $\begin{array}{c}\text { Energia } \\
\text { metabolizável }\end{array}$ & ${ }^{*} \mathrm{CV}$ & \multicolumn{2}{c}{$\begin{array}{c}\text { Relativo à energia } \\
\text { metabolizável formulada }\end{array}$} & $\begin{array}{c}\text { Relativo à energia } \\
\text { metabolizável dos } \\
\text { tratamentos }\end{array}$ \\
\hline${ }^{\circ} \mathrm{C}$ & $\mathrm{kcal} / \mathrm{kg}$ & $\%$ & $\mathrm{kcal} / \mathrm{kg}$ & $\%$ & $\mathrm{kcal} / \mathrm{kg}$ & $\%$ \\
80 & 3045 & 1,49 & 25 & 0,83 & - & - \\
100 & 3031 & 2,75 & 11 & 0,36 & 14,41 & $-0,47$ \\
120 & 3115 & 2,23 & 95 & 3,14 & 84,12 & 2,29 \\
140 & 2977 & 1,53 & -43 & $-1,42$ & $-137,73$ & $-2,23$ \\
\hline
\end{tabular}

*CV: Coeficiente de variação. 


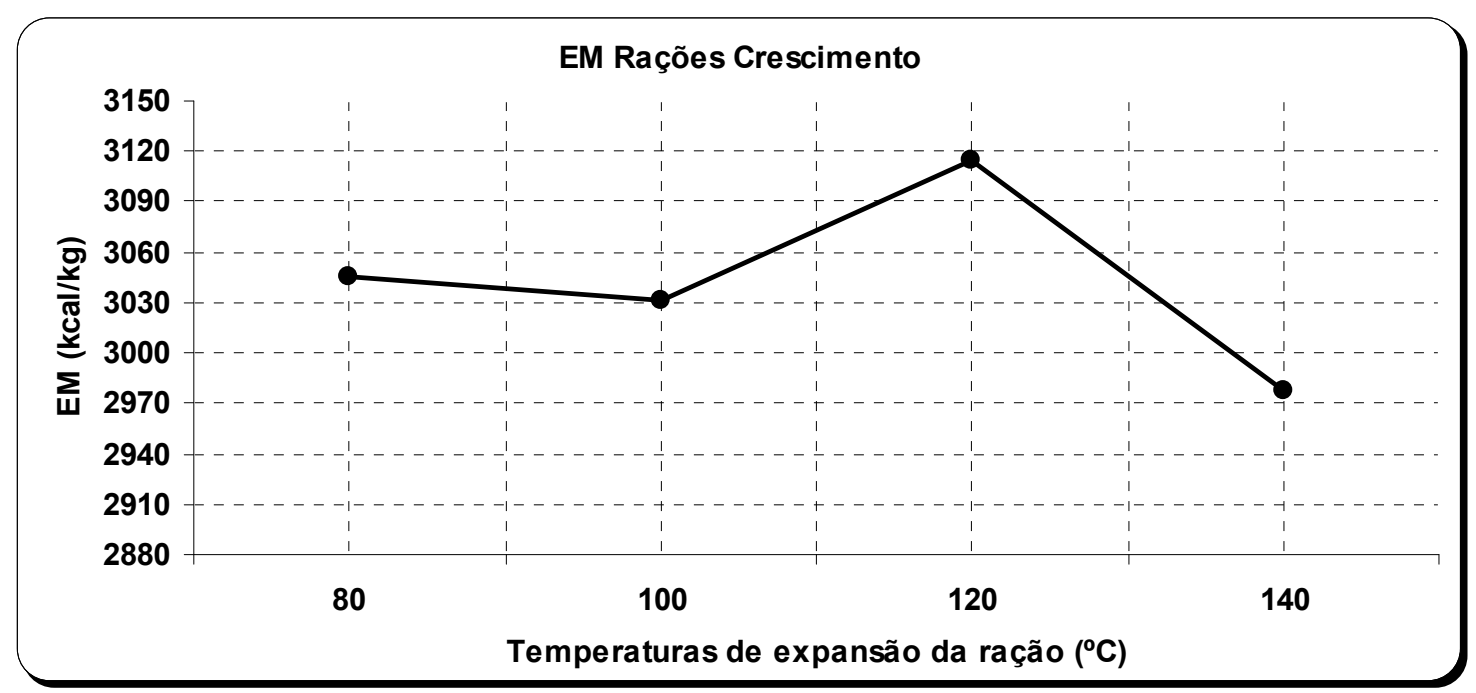

Figura 2. Valores da EMAn das rações de crescimento de frangos de corte (31-35 dias) para as diferentes temperaturas de expansão.

Esses resultados demonstram que, na fase de crescimento (31-35 dias), os frangos de corte maximizaram o aproveitamento energético das rações na temperatura de expansão de $120^{\circ} \mathrm{C}$ e que, em temperaturas acima desse nível, novamente ocorrem altas perdas da EMAn nas rações, que podem comprometer o consumo, a conversão alimentar, a deposição de proteína e, consequentemente, trazer grandes prejuízos econômicos pelo aumento da idade de abate.

A melhor utilização da energia contida nos alimentos pelas aves de maior idade pode ser explicada pela sua maturidade na produção de enzimas digestivas. A temperatura de expansão de $120^{\circ} \mathrm{C}$ proporcionou maior solubilização do amido e da proteína da ração, entretanto foram transformadas em energia mais eficientemente nas aves em crescimento do que nas da fase inicial.

A expansão também pode contribuir para o aumento da utilização energética de lipídeos contidos nos alimentos que compõem as rações. A significativa redução da concentração de microrganismos, pelo condicionamento da alta temperatura em curto período de tempo (HTSTHigh Temperature Short Time), é de fundamental importância. Muitas espécies de bactérias que contaminam os alimentos produzem lipases, que hidrolisam os triglicerídeos dos óleos e das gorduras, que consequentemente aumentam a concentração de ácidos graxos livres, reduzindo seus valores energéticos. A expansão também proporciona a inativação de enzimas, como as lipoxidases, responsáveis pela oxidação lipídica (Germany ,1992).

\section{CONCLUSÕES}

As temperaturas de expansão de rações de 80 a $100^{\circ} \mathrm{C}$ apresentaram os melhores valores de energia metabolizável corrigida (EMAn) para frangos com idade entre 15 e 19 dias (fase inicial), enquanto para idade de 31 a 35 dias (fase crescimento) foi de $120^{\circ} \mathrm{C}$.

\section{REFERÊNCIAS}

AMARAL, C.M.C. Extrusão e peletização de ração completa: efeitos no desempenho, na digestibilidade e no desenvolvimento das câmaras gástricas de cabritos Saanen. 2002. 57f. Dissertação (Mestrado em Zootecnia) Faculdade de Ciências Agrárias e Veterinárias, Universidade Estadual Paulista, Jaboticabal, SP.

BUDIÑO, F.E.L. Efeito da extrusão e umidade sobre a digestibilidade do milho em dietas para suínos. [s.l.]: Instituto de Zootecnia / CPDZD/APTA/SAA., 2000. 7p. (Informativo técnico, 217). 
GERMANY, M.P. Physical and chemical changes during expansion. Feed Int., v.23, p.1623, 1992.

GOELEMA, J.O.; SMITS, A.; VAESSEN, A. Effects of pressure toasting, expander treatment and pelleting on in vitro and in situ parameters of protein and starch in a mixture of broken peas, lupins and faba beans. Anim. Feed. Sci. Tech., v.78, p.109-126, 1999.

MATTERSON, L.D.; POTTER, L.M.; STUTZ, $\mathrm{N}$. W. The metabolizable energy of feed ingredients for chickens. Connecticut: Agricultural Experiment Station, 1965. 11p. (Research report, 7).

MOREIRA, I., ROSTAGNO, H.S., COELHO, D.T. Determinação dos coeficientes de digestibilidade, valores energéticos e índices de controle de qualidade do milho e soja integral processada a calor. Rev. Bras. Zootec., v.23, p.916-929, 1994.
NITSAN, Z.; BEM-AURAHAM, G.; ZOREF, $Z$.; NIR, I. Growth and development of the digestive organs and some enzymes in broiler chicks after hatching. Br. Poultr. Sci., v.32, p.515-523, 1991.

SOUZA, R.C.R.; ANDRADE, C.T. Investigação dos processos de gelatinização e extrusão de amido de milho. Polimeros, v.10, p.24-30, 2000.

ROSTAGNO, H.S. Tabelas brasileiras para aves e suínos: composição de alimentos e exigências nutricionais. 2.ed. Viçosa: UFV, Departamento de Zootecnia, 2005.

VAN, S.P.J. Carbohydrates. In: NUTRITIONAL ecology of the ruminant. New York: Cornell University, 1994. 164p. 